\title{
Toddler temperament, cognition and caregiver interaction predict impulsive functioning
}

Olson SL, Bates JE, Sandy JM, Schilling EM. Early and developmental precursors of impulsive and inattentive behaviour: from infancy to middle childhood. Journal of Child Psychology and Psychiatry 2002 May;43:435-47.

\section{QUESTION: What are the infancy and toddler-age precursors of inattention and impulsivity in school-age children?}

\section{Design}

Longitudinal cohort study.

\section{Setting}

Sources of funding: NIMH.

For correspondence: S Olson, Department of Psychology, University of Michigan. slolson@umich.edu
USA.

\section{Participants}

89 children participating in the Bloomington Longitudinal Study since infancy. Families were recruited using birth announcements when infants were 5-6 months old; $57 \%$ male; $51 \%$ first born.

Developmental correlates of inattentive and impulsive behaviour on laboratory measures at age 8

\begin{tabular}{lccc} 
Caregiver-child interactions & $\begin{array}{c}\text { Inhibitory } \\
\text { control }\end{array}$ & $\begin{array}{c}\text { Behavioural } \\
\text { control }\end{array}$ & Disengagement \\
Close contact (6 mths) & 0.02 & 0.06 & 0.09 \\
\hline Object stimulation (6 mths) & $0.28^{\star}$ & 0.12 & 0.02 \\
\hline Verbal stimulation (13-24 mths) & 0.22 & 0.03 & $-0.31^{\star}$ \\
\hline Non punitive (13-24 mths) & $0.26^{\star}$ & 0.09 & -0.14 \\
\hline Affection (13-24 mths) & 0.04 & 0.12 & 0.23 \\
\hline Child characteristics & & & \\
\hline Fussy / difficult (6 mths) & 0.15 & 0.01 & 0.06 \\
\hline Difficult (13-24 mths) & 0.02 & 0.06 & 0.14 \\
\hline Resisting control (13-24 mths) & -0.22 & 0.01 & 0.09 \\
\hline Observed difficultness (13-24 mths) & -0.23 & 0.04 & 0.09 \\
\hline Observed disengagement (13-24 mths) & $-0.36^{*}$ & 0.20 & $0.25^{\star}$ \\
\hline Child cognitive competence & & & \\
\hline Bayley Mental Scale (6 mths) & & & 0.03 \\
\hline Bayley Mental Scale (13-24 mths) & 0.07 & $-0.25^{\star}$ & $-0.39^{\star}$ \\
\hline
\end{tabular}

\section{Assessment of risk factors}

Demographic and family factors, child-parent interaction, child cognition and temperament were assessed at 6, 13 and 24 months and between 3-8 years of age using home observation, maternal report and laboratory tests. Mother-infant interaction and child characteristics were assessed during 3-hour home visits using naturalistic observation, the Mother Affectionate Contact scale, the Object Stimulation scale, the Child Characteristics questionnaire and the Bayley Mental Health scale.

\section{Main outcome measures}

Self regulatory competence at 8 years of age was measured using observation and laboratory tests of inhibitory control, behavioural control and attentional disengagement. Draw a Star Slowly and Matching Familiar Figures tests were used to assess inhibitory control. Task engagement and timing were monitored during a free play session to examine attentional disengagement. Behavioural control was assessed during restricted and unrestricted periods of a semi-structured work task.

\section{Main results}

Care-giver child interaction, child temperament and cognitive competence during infancy predicted variations in later impulsive functioning.

\section{Conclusions}

While child impulsivity is multidimensional, there are toddler-age precursors of later self regulatory competence.

\section{COMMENTARY}

This is one of a series of papers from the Bloomington Longitudinal Study focusing on temperament as one of a range of biological, developmental and family influences on longer term behavioural outcomes. Earlier reports from this study at 6 and 24 months focused on child impulsivity. In this paper, child temperament, parenting factors and cognitive and linguistic factors influenced self-regulatory competence at 8 years. Multiple measures including parent ratings, observational methods and cognitive testing were used. 'Impulsivity' was divided into inhibitory control, behavioural control and disengagement. While correlations between measures across time were relatively few and modest in size, the authors found some predictive relationships, which supported their transactional model of development. Inhibitory control was predicted by cognitive competence, early attentional control and interactional factors in parenting behaviour. Behavioural control or disengagement (measured via task behaviours) related only to early cognitive competence. Overall, the data had modest levels of continuity and supported the significance of early attentional control for later self-regulatory competence.

Although this research uses a non-clinical, predominantly middle class sample, the findings support Barkley's theory, developed from research with children with Attention Deficit Hyperactivity Disorder. This theory stresses the importance of 'executive competence' in early development for later self regulated behaviour and impulse control. The study therefore has implications not only for understanding normal development, but also shows where developmental processes can go wrong. From a clinical point of view, understanding the early precursors of self-regulation failure can help target intervention points. Nevertheless the modest predictive power of the precursors, even when researched with the detail and precision of this series, cautions against overconfidence in the antecedents of Attention Deficit Hyperactivity Disorder. The authors were mindful of subdimensions of self-regulation and 'executive competence.' Hence, this study makes a valuable contribution in emphasising that self-regulation is a multidimensional construct with various manifestations, diverse aetiologies and possible developmental pathways. It needs to be replicated in larger and more representative samples to account for the powerful influence of social determinants of child psychosocial health such as family structure and family supports; economic, educational and social disadvantage; parental mental and physical health, and community supports.

The capacity for what we call 'self regulation' is a significant influence on adaptive outcomes, but what exactly do we mean by 'self-regulation'? In this research, the term was operationally defined and carefully measured. Across the psychological literature, however, the construct is interpreted in many different ways encompassing emotional, attentional, effortful, social, cognitive and linguistic functions, to name just a few. More carefully defined constructs are needed to facilitate measurement and the connection(s) to later outcomes. Is it possible, for example, to have poor attentional regulation (disengagement in this paper) and good emotional self-regulation, or are they inextricable? This is one of the many questions for further research. 